\title{
Assessment of Dimensions and Image Quality of Coronary Contrast Catheters From Cineangiograms
}

\author{
Johan H.C. Reiber, PhD, Cornelis J. Kooijman, MSc, Ad den Boer, \\ BSc, and Patrick W. Serruys, MD
}

\begin{abstract}
In the quantitative assessment of coronary arterial dimensions from coronary cineangiograms, the contrast catheter is usually used as a scaling device, requiring the definition of the catheter contours by semi- or fully automated contour detection procedures. The image quality of the $x$-ray radiated catheter is dependent on the catheter material, concentration of the contrast agent in the catheter, and kilovoltage of the $x$-ray source. The effects of these variables on the image quality and accuracy of the size-measurement of the filmed catheters were studied for four different catheter materials: woven dacron (wd), polyvinylchloride (pv), polyurethane (pu), and nylon. The following parameters were studied: measured size, image contrast, and average brightness gradient along the edges of the displayed catheters. The average differences of the angiographically measured size with the true size for the wd, pv, $\mathrm{pu}$, and nylon catheters were $+0.2,-3.2,-3.5$, and $+9.8 \%$, respectively. The image contrast at various fillings of the catheters was roughly identical for the $\mathrm{wd}, \mathrm{pv}$, and pu catheters, and significantly lower for the nylon catheter. Image gradient was highest for the wd catheter, followed by the pv and pu catheters, and lowest for the nylon catheter.

From these data it may be concluded that the woven dacron catheter is most suitable for quantitative coronary angiographic studies. The polyvinylchloride and polyurethane catheters perform about equally well but slightly less than the woven dacron catheter. The nylon catheter should not be used for such quantitative studies.
\end{abstract}

Key words: quantitative coronary cineangiography, contrast catheters, image quality, image processing

\section{INTRODUCTION}

Coronary contrast catheters have been used increasingly for calibration purposes in the quantitative assessment of coronary arterial dimensions [1-8]. However, until

From Erasmus University, and University Hospital Dijkzigt, Rotterdam, The Netherlands.

This project has been supported in part by the Dutch Heart Foundation under grant no. 80.129.

Address reprint requests to Johan H.C. Reiber, PhD, Erasmus University, CVR, Ee 2328, P.O. Box 1738, 3000 DR Rotterdam, The Netherlands.

Received May 1, 1985; revision accepted June 10, 1985.

(C) 1985 Alan R. Liss, Inc. 
today no extensive study has been performed on the accuracy of these measurements from coronary cineangiograms, nor on the effect of catheter material, contrast filling of the catheter, and $\mathrm{kV}$-setting of the $\mathrm{x}$-ray source on image quality of the irradiated catheter and thus on the accuracy of measurement. It is the purpose of this paper to describe such results on four different materials, filmed at various settings of the quality of the x-ray system and filled with various concentrations of contrast agent and with water and air.

\section{METHODS}

Mid-portions of the four contrast catheters were taped on a block of perspex with dimensions $10 \times 10 \times 10 \mathrm{~cm}$. The height of the $\mathrm{x}$-ray table was adjusted such that the catheters could be filmed in the isocenter of the x-ray system. Five different fillings were used for the catheters: 1) only air inside; 2) filled with water; and filled with three different concentrations of a contrast agent (Urografin-76, Schering AG, Berlin, Germany); 3) $370 \mathrm{mg} \mathrm{I} / \mathrm{cc}$ (100\% concentration); 4) $185 \mathrm{mg} \mathrm{I} / \mathrm{cc}$ (50\% concentration); and 5) $92.5 \mathrm{mg} \mathrm{I} / \mathrm{cc}$ (25\% concentration). Each situation was filmed at four different kilovoltages, ranging from 55 to $81 \mathrm{kV}$. For calibration purposes, a centimeter grid was filmed on top of the perspex block after the catheter measurements had been performed.

The cinefilms were analyzed with the Coronary Angiography Analysis System (CAAS), which has been described in detail elsewhere [5-7]. Briefly, the cinefilm was mounted on a specially constructed cine-video converter. A selected cineframe was optically magnified with a factor of $2 \sqrt{ } 2$ and a portion of the image, encompassing a catheter segment to be analyzed, was converted into video format by means of a high-resolution video camera attached to a movable $x-y$ stage. The center square of the resulting analog video image is digitized in matrix size of $512 \times 512$ picture elements (pixels) with 8 bits (256 levels) brightness resolution and displayed on a video monitor. At several crucial moments in the analysis procedure, user-interaction is possible by means of a writing tablet.

The calibration factor for the study was determined by manual definition of three pairs of points on neighboring vertical lines of the centimeter grid in the center of the image with the writing tablet. The calibration factor was thus expressed as $\mathrm{mm} / \mathrm{pixel}$. As a next step, the boundaries of a portion of a given catheter were detected automatically with the coronary artery detection algorithm over a length of approximately $1.0 \mathrm{~cm}$ (Fig. 1).

This arterial contour detection procedure requires the user to indicate a number of center positions in the optically magnified catheter segment. A smoothed version of this centerline determines regions of interest of size $96 \times 96$ pixels encompassing the catheter segment to be transferred to the host computer (PDP 11/44) for edgedefinition purposes. To decrease spatial fluctuations due to quantum noise, the digital data are smoothed spatially with a $5 \times 5$ median filter. Subsequently, the digital data are resampled along straight lines, denoted scanlines, perpendicular to the local centerline directions. Contours of the catheter segment along the scanlines are determined on the basis of the weighted sum of first and second difference functions applied to the resampled brightness information using so-called minimal cost criteria [5]. 


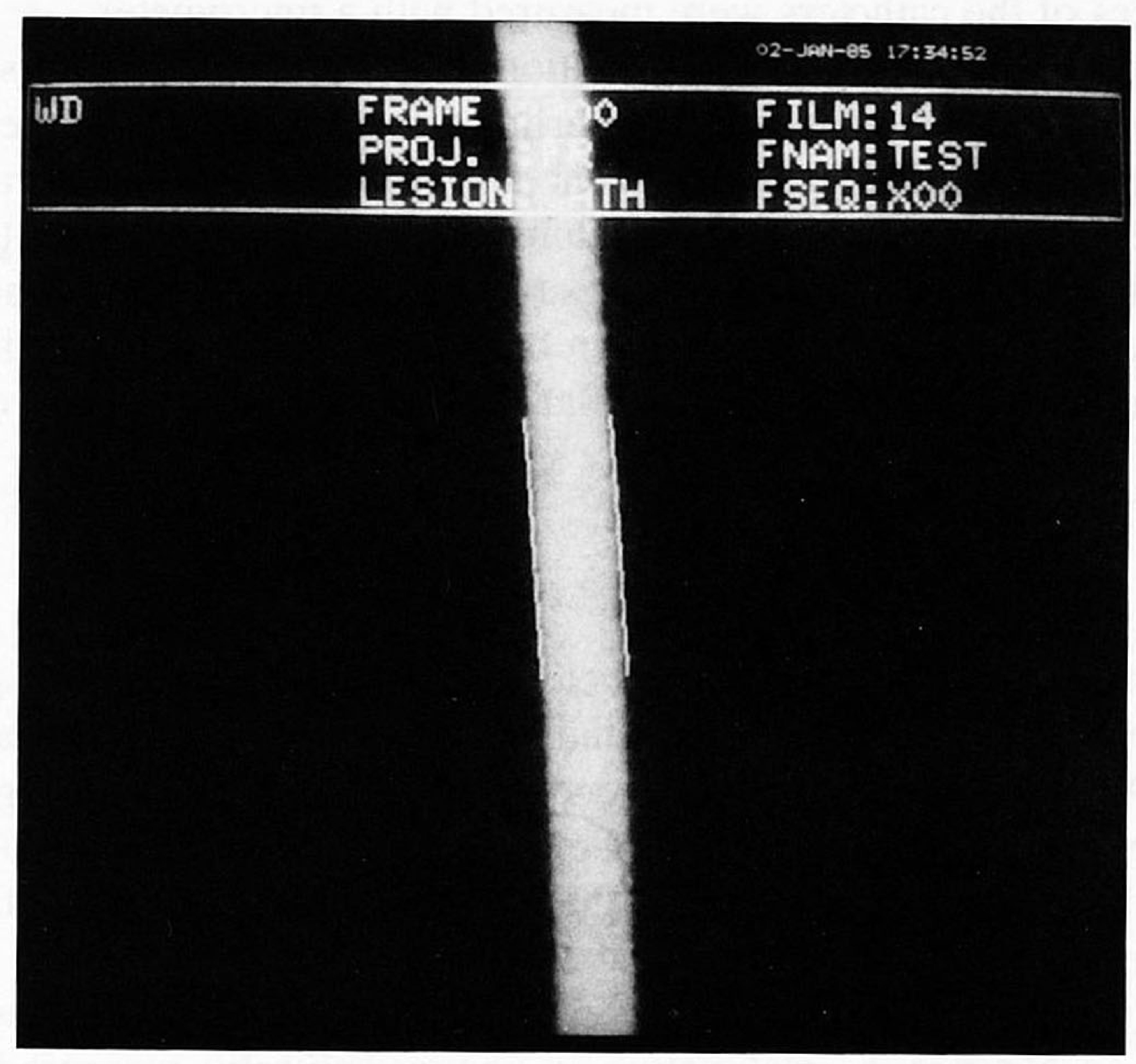

Fig. 1. Example of detected contours along a portion of one of the contrast catheters.

If the user does not agree with part of the detected contours, these erroneous positions may be corrected interactively with the writing tablet. On the basis of the corrected contours, a new centerline is computed and the detection process repeated to minimize the influence of the initially user-indicated center positions on the arterial contours. Finally, a smoothing procedure is applied to each of the detected contours and the resulting positions corrected for pincushion distortion. Figure 1 shows the detected contours along a portion of a contrast catheter.

From the analyzed portion of a contrast catheter the following parameters were measured:

1. Mean diameter $(\mathrm{mm})$.

2. Average brightness level along centerline in catheter (B. cath).

3. Average background brightness level (B. bkg), measured 10 pixels $( \pm 0.6 \mathrm{~mm})$ outside of the detected contours.

4. Difference between B. cath and B. bkg, being a measure for image contrast.

5. Average value of the weighted sum of first and second difference functions for the left-hand side contour positions $(\mathrm{GRAD}(\mathrm{L}))$.

6. Average value for the weighted sum of first and second difference functions for the right-hand side contour positions $(\operatorname{GRAD}(\mathrm{R}))$.

\section{MATERIALS}

Four catheters fabricated from different materials were used for this study: A) woven dacron, Sones 7F catheter (USCI Int., Inc., Billerica, MA), B) polyvinylchloride, Judkins 7.3F catheter (Cook Inc., Bloomington, IN), C) polyurethane, femoral-left coronary $8 \mathrm{~F}$ catheter (Cordis Corp., Miami, FL), and D) nylon, Alvaflo Judkins 7F catheter (Mallinckrodt GmbH, Grossostheim, West Germany). 
The true sizes of the catheters were measured with a micrometer.

Figure 2 shows the brightness distribution along a scanline across an analyzed catheter segment perpendicular to the centerline direction for each of the four catheter materials filled with $100 \%$ contrast agent and with air. In each graph the pixel positions along the scanline are plotted along the horizontal axis and the brightness levels along the vertical axis. From these eight graphs the differences in image contrast between the various materials can be appreciated, as well as the differences in the brightness distribution for a particular segment filled with $100 \%$ contrast agent or with air.

\section{RESULTS}

In Table I the true sizes of the four catheter segments, measured with a micrometer, are listed, as well as the average value and standard deviation of the values assessed with the CAAS and the average difference between the true and angiographically measured sizes. For each catheter a total of 20 measurements was available from the air- and water-filled catheters and from the catheters filled with the different concentrations of contrast agent $(92.5,185$, and $370 \mathrm{mg} \mathrm{I} / \mathrm{cc})$, each filmed at four different kilovoltages (range 55-81 kV). Best results were obtained for the woven dacron catheter with an average overestimation in angiographically measured size of only $+0.2 \%$, followed by the polyvinylchloride and polyurethane catheters, with average underestimations of $-3.2 \%$ and $-3.5 \%$, respectively, while the nylon catheter was overestimated by $9.8 \%$. Similarly, the standard deviation of the computer-assisted measurements was smallest $(=0.02 \mathrm{~mm})$ for the woven dacron catheter, followed by the polyvinylchloride and polyurethane catheters $(0.03 \mathrm{~mm})$, while the highest value was obtained for the nylon catheter $(0.05 \mathrm{~mm})$.

In Table II these dimensional measurements have been subdivided according to the five different fillings of the catheter segments. The measurements were averaged over the results from the four different kilovoltages at which these segments were filmed. The mean values of these results are presented graphically in Figure 3; this graph depicts the variability of the measurements as a function of the filling of the catheter. The maximal difference between mean values for the various situations is less than or equal to $0.04 \mathrm{~mm}$ for the woven dacron, the polyvinylchloride, and polyurethane catheters, and more than double that value $(0.09 \mathrm{~mm})$ for the nylon catheter.

In Table III the image contrast values of the $\mathrm{x}$-rayed and filmed catheters, averaged over the four kilovoltage measurements, are listed for the four catheters according to the five different fillings. Image contrast was defined by the difference of the average brightness level along the centerline of the analyzed catheter segment and of the average brightness level measured in the backgroud, at 10 pixels $( \pm 0.6 \mathrm{~mm})$ from the defined contour positions. These results have been depicted graphically in Figure 4. It can be concluded from Table III and Figure 4 that for all four catheters image contrast decreases with the $\mathrm{x}$-ray absorption coefficient of the filling of the catheter. The woven dacron and polyvinylchloride catheters demonstrate image brightness levels of similar magnitude, while the image brightness of the polyurethane catheter filled with contrast medium of at least $50 \%$ concentration is higher than that for the first two mentioned catheters and similar for the water and air fillings. The image contrast of the nylon catheter is significantly lower for all fillings as compared to the other three materials. 

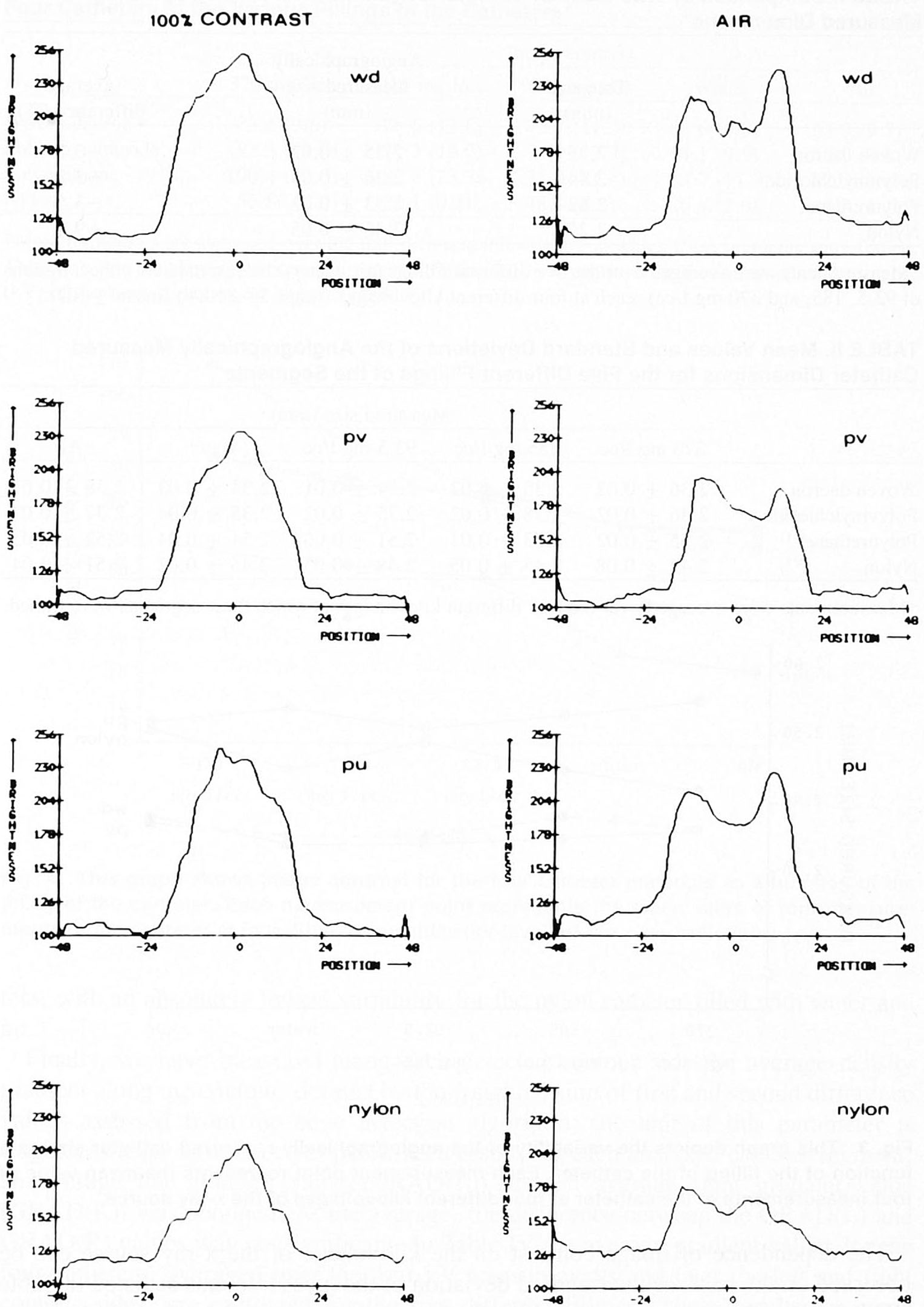

Fig. 2. Examples of brightness distribution along scanlines perpendicular to the centerline directions for the four different catheters, filled with $100 \%$ contrast agent (left column) and with air (right column). The vertical order of the graphs represents the different materials (from top to bottom): woven dacron (wd), polyvinylchloride (pv), polyurethane (pu), and nylon, respectively. In each graph, the pixel positions along the scanline are plotted along the horizontal axis and the brightness levels along the vertical axis. 
TABLE I. Comparison of True Sizes of Catheter Segments With Angiographically Measured Dimensions*

\begin{tabular}{lccc}
\hline & $\begin{array}{c}\text { True size } \\
(\mathrm{mm})\end{array}$ & $\begin{array}{c}\text { Angiographically } \\
\text { measured size } \\
(\mathrm{mm})\end{array}$ & $\begin{array}{c}\text { Average } \\
\text { difference }(\%)\end{array}$ \\
\hline Woven dacron & 2.35 & $2.35 \pm 0.02$ & +0.2 \\
Polyvinylchloride & 2.44 & $2.36 \pm 0.03$ & -3.2 \\
Polyurethane & 2.62 & $2.53 \pm 0.03$ & -3.5 \\
Nylon & 2.25 & $2.46 \pm 0.05$ & +9.8 \\
\hline
\end{tabular}

* Measurements were averaged over the five different fillings (air, water, contrast medium concentrations of $92.5,185$, and $370 \mathrm{mg} \mathrm{I} / \mathrm{cc}$ ), each at four different kilovoltages (range 55-81 kV) (mean $\pm \mathrm{SD}$ ).

TABLE II. Mean Values and Standard Deviations of the Angiographically Measured Catheter Dimensions for the Five Different Fillings of the Segments*

\begin{tabular}{lccccc}
\hline & \multicolumn{5}{c}{ Measured size $(\mathrm{mm})$} \\
\cline { 2 - 6 } & $370 \mathrm{mg} \mathrm{I} / \mathrm{cc}$ & $185 \mathrm{mg} \mathrm{I} / \mathrm{cc}$ & $92.5 \mathrm{mg} \mathrm{I} / \mathrm{cc}$ & Water & Air \\
\hline Woven dacron & $2.36 \pm 0.02$ & $2.35 \pm 0.02$ & $2.34 \pm 0.01$ & $2.34 \pm 0.03$ & $2.38 \pm 0.01$ \\
Polyvinylchloride & $2.36 \pm 0.02$ & $2.38 \pm 0.02$ & $2.35 \pm 0.02$ & $2.35 \pm 0.04$ & $2.37 \pm 0.02$ \\
Polyurethane & $2.55 \pm 0.02$ & $2.53 \pm 0.03$ & $2.51 \pm 0.06$ & $2.54 \pm 0.04$ & $2.52 \pm 0.03$ \\
Nylon & $2.42 \pm 0.08$ & $2.45 \pm 0.05$ & $2.48 \pm 0.03$ & $2.45 \pm 0.02$ & $2.51 \pm 0.04$ \\
\hline
\end{tabular}

*Measurements were averaged over the four different kilovoltages at which these segments were filmed.

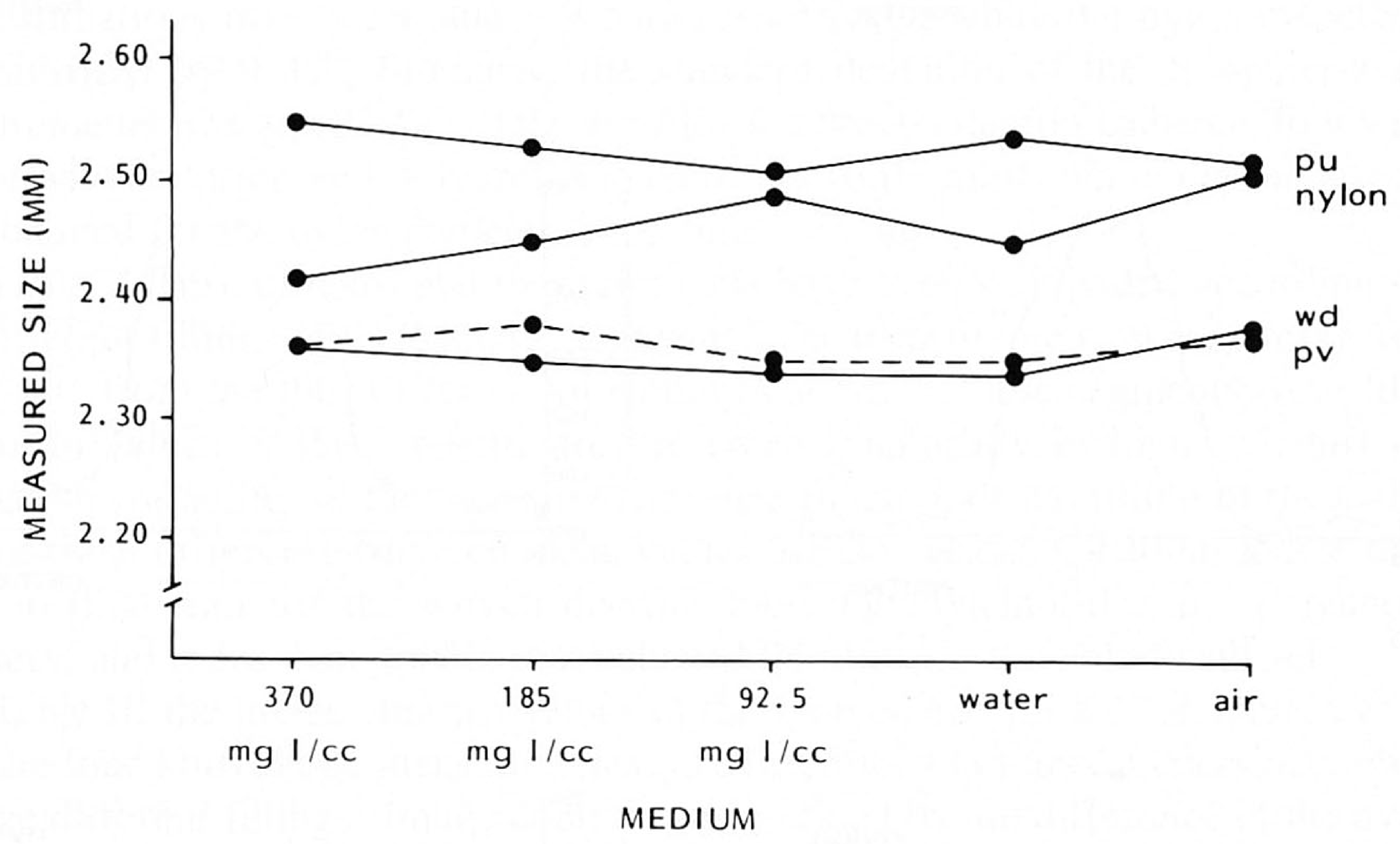

Fig. 3. This graph depicts the variability of the angiographically measured catheter size as a function of the filling of the catheter. Each measurement point represents the mean value of four measurements of the catheter at four different kilovoltages of the $x$-ray source.

The dependence of image contrast on the kilovoltage of the x-ray source can be observed on the basis of the standard deviation of the measurements as listed in Table III. It is clear from this table that the influence of the quality of the x-ray radiation is similar for all five fillings for the woven dacron and polyvinylchloride catheters. The kilovoltage-dependence for the polyurethane catheter is roughly twice as high for all five fillings. On the other hand, the contrast-filled nylon catheter shows a dependence again approximately equal to that of the woven dacron and polyvinylchloride cathe- 
TABLE III. Mean Values and Standard Deviations of the Measured Image Contrast for the Four Catheters at the Various Fillings of the Catheters*

\begin{tabular}{lccccc} 
& \multicolumn{5}{c}{ Image contrast } \\
\cline { 2 - 6 } & $370 \mathrm{mg} \mathrm{I} / \mathrm{cc}$ & $185 \mathrm{mg} \mathrm{I} / \mathrm{cc}$ & $92.5 \mathrm{mg} \mathrm{I} / \mathrm{cc}$ & Water & Air \\
\hline Woven dacron & $83.6(9.6)$ & $75.6(12.8)$ & $73.7(11.3)$ & $64.0(8.9)$ & $63.0(9.7)$ \\
Polyvinylchloride & $82.3(11.0)$ & $77.3(13.0)$ & $71.9(12.7)$ & $64.1(9.9)$ & $58.0(9.1)$ \\
Polyurethane & $100.4(22.3)$ & $87.8(23.7)$ & $75.0(21.4)$ & $63.7(17.7)$ & $62.5(18.6)$ \\
Nylon & $55.8(12.3)$ & $52.1(9.3)$ & $48.4(8.3)$ & $26.4(2.0)$ & $21.8(1.1)$ \\
\hline
\end{tabular}

*Measurements were averaged over the four different kilovoltages at which these segments were filmed. Therefore, the standard deviation, (shown in parentheses), is a measure for the influence of the quality $(\mathrm{kV})$ of the $\mathrm{x}$-ray radiation on image contrast.

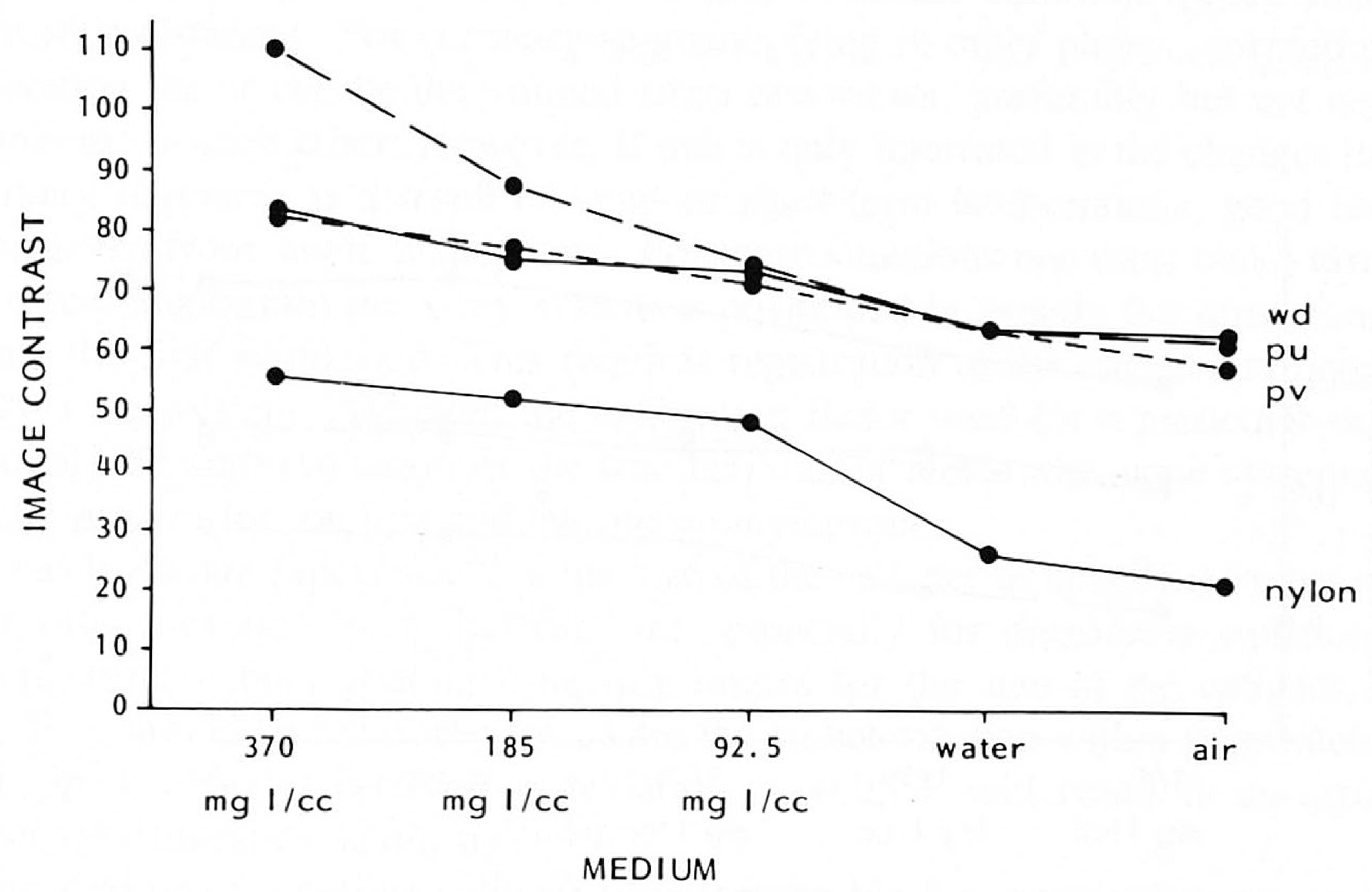

Fig. 4. This graph shows image contrast for the four catheter materials as a function of the filling of the catheter. Each measurement point represents the mean value of four measurements of the catheter at four different qualities (kV-level) of the $\mathrm{x}$-ray radiation.

ters, with an absolutely lowest variability for the nylon catheter filled with water and air.

Finally, we have measured along each detected contour side the average density gradient along the contour, defined by the weighted sum of first and second difference values assessed from the edge detection algorithm; the unit of this parameter is brightness level difference per pixel. As a result, for each analyzed catheter segment, an average left gradient value $(\mathrm{GRAD}(\mathrm{L}))$ and an average right gradient value $(G R A D(R))$ was obtained. At the average, the difference between the GRAD $(L)$ and $\mathrm{GRAD}(\mathrm{R})$ values was nonsignificant. In Table IV the average gradient values for the four catheters, averaged over the four $\mathrm{kV}$ measurements and over the left and right contour sides, are presented for the five different fillings. These results are again depicted graphically in Figure 5.

It is clear from Figure 5 that the highest gradient levels are obtained with the woven dacron catheter, followed by the polyvinylchloride and polyurethane catheters; the nylon catheter again shows the poorest results. For all catheter materials, the bright- 
TABLE IV. Mean Values and Standard Deviations of the Average Image Gradient at the Detected Contour Positions for the Four Catheter Materials at the Various Fillings of the Catheters.

\begin{tabular}{lrrrrr}
\hline & \multicolumn{5}{c}{ Average gradient } \\
\cline { 2 - 6 } & $370 \mathrm{mg} \mathrm{I} / \mathrm{cc}$ & $185 \mathrm{mg} \mathrm{I} / \mathrm{cc}$ & $92.5 \mathrm{mg} \mathrm{I} / \mathrm{cc}$ & Water & \multicolumn{1}{c}{ Air } \\
\hline Woven dacron & $14.9(1.4)$ & $16.4(2.4)$ & $18.1(3.2)$ & $19.4(3.0)$ & $19.1(3.5)$ \\
Polyvinylchloride & $10.5(1.5)$ & $11.6(2.0)$ & $12.7(2.0)$ & $13.4(2.9)$ & $12.7(2.0)$ \\
Polyurethane & $10.9(2.3)$ & $12.2(3.0)$ & $12.2(2.8)$ & $13.0(4.0)$ & $13.1(3.6)$ \\
Nylon & $5.4(1.7)$ & $6.4(1.7)$ & $7.4(1.4)$ & $7.6(2.3)$ & $7.9(1.4)$ \\
\hline
\end{tabular}

Measurements were averaged over the four different kilovoltages at which these segments were filmed. Therefore, the standard deviation, (shown in parentheses), is a measure for the influence of the quality $(\mathrm{kV})$ of the $\mathrm{x}$-ray radiation on the image gradient.

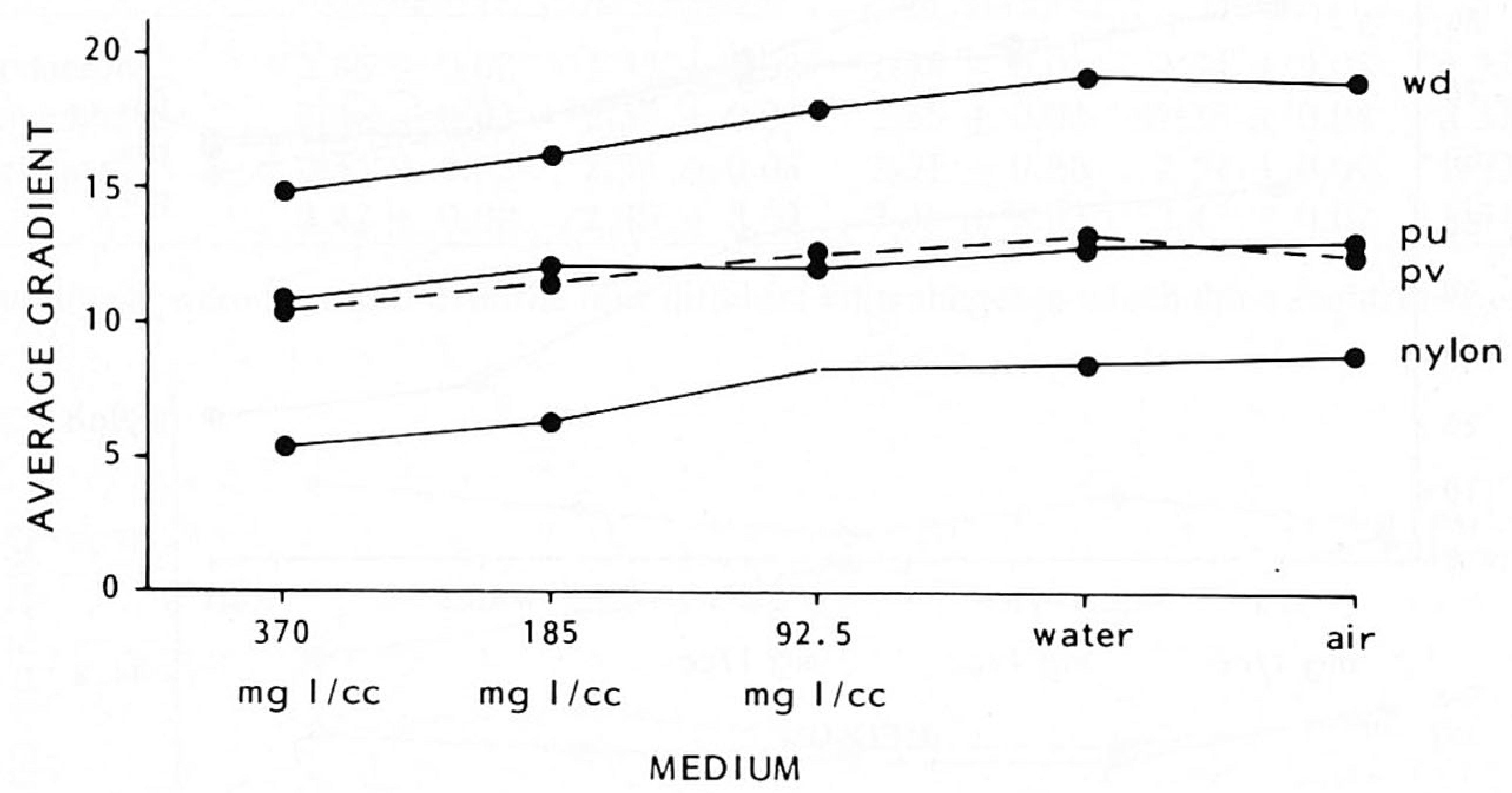

Fig. 5. Average brightness gradient at the detected contour positions for the four catheter materials as a function of the filling of the catheter. Each measurement point represents the mean value of four measurements of the catheter at four different qualities (kV-level) of the $x$ ray radiation.

ness gradient increases with decreasing $\mathrm{x}$-ray absorption coefficient of the filling of the catheter.

The standard deviations of the measurements listed in Table IV are a measure for the influence of the quality of the $\mathrm{x}$-ray radiation ( $\mathrm{kV}$-level $\mathrm{x}$-ray source) on the gradient level. It is apparent that two conclusions may be drawn: 1) for the woven dacron, polyvinylchloride, and polyurethane catheters, the standard deviations increase with decreasing $\mathrm{x}$-ray absorption coefficients for the contrast-filled catheters; and 2) for all four materials the highest values of the variations are measured for the water- and air-filled catheters.

\section{DISCUSSION}

To evaluate the efficacy of modern therapeutic procedures in the catheterization laboratory [9-11], the effects of vasoactive drugs [12,13], as well as the effects of 
short- and long-term interventions on the regression or progression of coronary artery disease [14], absolute coronary artery dimensions must be assessed from the repeat coronary cineangiograms with high accuracy [6]. Moreover, it has been shown recently that the minimal cross-sectional area of an individual coronary obstruction is the best predictor of its physiological significance $[15,16]$. To this end, a calibration procedure must be available to assess these absolute values from the analyzed cineframes. For these purposes, the size of the contrast catheter visible in these images is used most frequently. Strictly speaking, the calibration factor computed from a single view is only applicable for objects in the plane of the analyzed catheter segment parallel to the image intensifier input screen. The change in magnification for two objects located at different points along the x-ray beam axis is about $1.5 \%$ for each centimeter that separates the objects axially with the commonly used focus-image intensifier distances. For coronary segments lying in other planes, corrections to the calibration factor can be determined from two views, preferably but not necessarily orthogonal to each other. However, if one is only interested in the changes in sizes of coronary segments as a result of long- or short-term interventions, good results can be achieved from single plane views. For these situations one must make sure that for the repeat angiogram the $\mathrm{x}$-ray system is positioned in exactly the same geometry as during the first angiogram. This requires registration of the angles and height levels of the x-ray system. Although the calibration factor used for a particular segment is then only an approximation of the true calibration factor, the same systematic error will be present for the first and the repeat angiogram.

It has been our experience that the size of the catheter as specified by the manufacturer often deviates from the true size, especially for disposable catheters. If the manufacturer cannot guarantee narrow ranges for the size of the catheter, e.g., \pm $0.05 \mathrm{~F}$, it should be measured following the catheterization with a micrometer. For a $5.5 \mathrm{~F}$ tip of a Sones catheter, a deviation by $0.05 \mathrm{~F}$ will result in an error in the computed calibration factor by $0.9 \%$.

For a coronary contrast catheter to be acceptable for quantitative coronary angiographic studies, it must fulfill a number of criteria:

1. The standard deviation of a series of measurements as performed in this study, that is, with different fillings of the contrast catheter and filmed with different $x$-ray qualities, must be lower than a certain absolute threshold, for example $0.03 \mathrm{~mm}$, being $0.1 \mathrm{~F}$.

2. The lowest image contrast measured during such an evaluation study must be higher than a certain threshold.

3. The average gradient measured during the evaluation study must be above a lower threshold value.

The following critique must be made with respect to the three points mentioned above.

Concerning point 1 . It is possible that the evaluation study for a given catheter shows that the standard deviation of the measurements is equal to or below the threshold of $0.03 \mathrm{~mm}$, but that a systematic error is observed in the mean values of these measurements. The polyvinylchloride and polyurethane catheters used in this study show such a response. If this is the case, then the systematic error may be corrected for in the coronary analysis software package for this given type of catheter. This means that such correction factors must be available for the different types of catheters to be used in a quantitative coronary angiographic study. 
Concerning point 2 . In this comparative study on the image quality of different catheter materials, the measured image quality has been computed in terms of digitized brightness levels. It will be clear that such values are dependent on the illumination of the analyzed cineframes. The four catheter segments used in this study were analyzed under identical levels of image illumination. However, a general applicable threshold level for the image quality cannot be derived from our data. A better measure would be to describe the image quality of a catheter segment in terms of absolute optical density differences in the cineframes, requiring a densitometric analysis of the cinefilm.

Such techniques are under development in our center. For these purposes we have designed a cinefilm-sensitometer that allows the exposure of the first 21 frames of a cinefilm with a light source having the same color temperature as the output screen of the image intensifier. These calibration frames are exposed according to an exponential function:

$$
E(p)=k \cdot(\sqrt{ } 2)^{-n}
$$

with $n$ being the frame sequence number $(0 \leqq n \leqq 20)$. These frames are processed photographically simultaneously with the rest of the coronary cineangiogram, so that the film development process is identical for both the calibration frames and the clinical or experimental cineframes. As a first step of the analysis procedure for one or more cineframes of a given cinefilm, these calibration frames are digitized and stored in the computer. On the basis of these calibration data, for each point in a coronary or catheter cineframe the absolute density level can be computed from the measured brightness level, under the restriction that the illumination of the cinefilm remains constant over the calibration and analysis periods.

Concerning point 3 . Similarly as described under point 2 , the average gradient levels in this study are not generally applicable for the purpose of defining a threshold level. However, as soon as the measurements can be described in terms of absolute density levels, an absolute threshold level can be defined.

On the basis of our evaluation data, we may conclude that the woven dacron is most suitable for quantitative coronary angiographic studies. The polyvinylchloride and polyurethane catheters perform about equally well, but slightly less than the woven dacron catheter. The nylon catheter should not be used for these studies.

\section{ACKNOWLEDGMENTS}

The authors wish to thank Mrs. M.J. Kanters-Stam and Mrs. S.M. Spierdijk for their secretarial assistance in the preparation of this manuscript.

\section{REFERENCES}

1. Brown BG, Bolson E, Frimer M, Dodge HT: Quantitative coronary arteriography. Estimation of dimensions, hemodynamic resistance, and atheroma mass of coronary artery lesions using the arteriograms and digital computation. Circulation 55:329-337, 1977.

2. Selzer RH, Blankenhorn DH, Crawford DW, Brooks SH, Barndt R: Computer analysis of cardiovascular imagery. Proceedings of the Caltech/JPL Conference on Image Processing Technology, Data Sources and Software for Commercial and Scientific Applications, Pasadena, Nov 3-5, 1976, pp 1-20. 
3. Ledbetter DC, Selzer RH, Gordon RM, Blankenhorn DH, Sanmarco ME: Computer quantitation of coronary angiograms. In Miller HA, Schmidt EV, Harrison DC (eds): "Noninvasive Cardiovascular Measurements." SPIE 167, Bellingham, WA, 1978, pp 27-36.

4. Smith DN, Colfer H, Brymer JF, Pitt B, Kliman SH: A semiautomatic computer technique for processing coronary angiograms. Comp Cardiol:325-328, 1982.

5. Kooijman CJ, Reiber JHC, Gerbrands JJ, Schuurbiers JCH, Slager CJ, den Boer A, Serruys PW: Computer-aided quantitation of the severity of coronary obstructions from single view cineangiograms. First IEEE Comp. Soc. Int. Symp. on Medical Imaging and Image Interpretation, IEEE Cat. No. 82 CH1804-4, 1982, pp 59-64.

6. Reiber JHC, Serruys PW, Kooijman CJ, Wijns W, Slager CJ, Gerbrands JJ, Schuurbiers JCH, den Boer A, Hugenholtz PG: Assessment of short-, medium- and long-term variations in arterial dimensions from computer-assisted quantitation of coronary cineangiograms. Circulation 71:280$288,1985$.

7. Reiber JHC, Kooijman CJ, Slager CJ, Gerbrands JJ, Schuurbiers JCH, den Boer A, Wijns W, Serruys PW, Hugenholtz PG: Coronary artery dimensions from cineangiograms; methodology and validation of a computer-assisted analysis procedure. IEEE Trans Med Imaging MI-3:131-141, 1984.

8. Reiber JHC, Kooijman CJ, Slager CJ, Gerbrands JJ, Schuurbiers JCH, den Boer A, Wijns W, Serruys PW: Computer assisted analysis of the severity of obstructions from coronary cineangiograms: A methodological review. Automedica 5:219-238, 1984.

9. Serruys PW, Booman F, Troost GJ, Reiber JHC, Gerbrands JJ, van den Brand M, Cherrier F, Hugenholtz PG: Computerized quantitative coronary angiography applied to percutaneous transluminal coronary angioplasty: Advantages and limitations. In Kaltenbach M, Grüntzig A, Rentrop K, Bussmann WD (eds): "Transluminal Coronary Angioplasty and Intracoronary Thrombolysis. Coronary Heart Disease IV." Berlin: Springer-Verlag, 1982, pp 110-124.

10. Serruys PW, Wijns W, van den Brand M, Ribeiro V, Fioretti P, Simoons ML, Kooijman CJ, Reiber JHC, Hugenholtz PG: Is transluminal coronary angioplasty mandatory after successful thrombolysis? Br Heart J 50:257-265, 1983.

11. Wijns W, Serruys PW, van den Brand M, Reiber JHC, Suryapranata H, Hugenholtz PG: Progression to complete coronary obstruction without myocardial infarction in patients who are candidates for percutaneous transluminal angioplasty: A 90-day angiographic follow-up. In Roskamm H (ed): "Prognosis of Coronary Heart Disease-Progression of Coronary Arteriosclerosis." Berlin: Springer-Verlag, 1983, pp 190-195.

12. Wijns W, Serruys PW, Reiber JHC, Van den Brand M, Simoons ML, Kooijman CJ, Balakumaran K, Hugenholtz PG: Quantitative angiography of the left anterior descending coronary artery: Correlations with pressure gradient and exercise thallium scintigraphy. Circulation 71:273-279, 1985 .

13. Serruys PW, Hooghoudt TEH, Reiber JHC, Slager C, Brower RW, Hugenholtz PG: Influence of intracoronary nifedipine on left ventricular function, coronary vasomotility, and myocardial oxygen consumption. Br Heart J 49:427-441, 1983.

14. Serruys PW, Lablanche JM, Reiber JHC, Bertrand ME, Hugenholtz PG: Contribution of dynamic vascular wall thickening to luminal narrowing during coronary arterial vasomotion. Z Kardiol 72:116-123, 1983.

15. Marcus M, Wright C, Doty D, Eastham C, Laughlin D, Krumm P, Fastenow C, Brody M: Measurements of coronary velocity and reactive hyperemia in the coronary circulation of humans. Circ Res 49:877-891, 1981.

16. Harrison DG, White CW, Hiratzka LF, Doty DB, Barnes DH, Eastham CL, Marcus ML: The value of lesion cross-sectional area determined by quantitative coronary angiography in assessing the physiologic significance of proximal left anterior descending coronary arterial stenoses. Circulation 69:1111-1119, 1984. 